\title{
Influence of hormonal functional status on survival in adrenocortical carcinoma: systematic review and meta-analysis
}

\author{
T Vanbrabant', M Fassnacht'2,3,4, G Assie ${ }^{5,6}$ and $\mathrm{O}$ M Dekkers ${ }^{1,7}$ \\ 'Department of Clinical Epidemiology, Leiden University Medical Center, Leiden, The Netherlands, 'Division of Endocrinology and \\ Diabetes, Department of Internal Medicine I, University Hospital, ${ }^{3}$ Comprehensive Cancer Center Mainfranken, University of \\ Würzburg, Würzburg, Germany, ${ }^{4}$ Central Laboratory, University Hospital Würzburg, Würzburg, Germany, ${ }^{5}$ Department of \\ Endocrinology, Reference Center for Rare Adrenal Diseases, Reference Center for Rare Adrenal Cancers, Hôpital \\ Cochin, Assistance Publique Hôpitaux de Paris, Paris, France, ${ }^{6}$ Institut Cochin, Institut National de la Santé et de la \\ Recherche Médicale U1016, Centre National de la Recherche Scientifique UMR8104, Université Paris Descartes, \\ Sorbonne Paris Cité, Paris, France, and 7 Division Internal Medicine, Department Endocrinology \& Metabolism, \\ Leiden University Medical Center, Leiden, The Netherlands \\ Correspondence \\ should be addressed \\ to $\mathrm{O} M$ Dekkers \\ Email \\ o.m.dekkers@lumc.nl
}

\begin{abstract}
Objective: Adrenocortical carcinoma (ACC) is a malignancy with a poor prognosis. Many publications in ACC report on risk factors for a poor outcome; one risk factor studied is hormonal hypersecretion (cortisol, sex-hormones, steroid precursors or aldosterone). The aim of this systematic review was to study the association between hormonal secretion and recurrence or mortality in ACC.

Design: Systematic review and meta-analysis. We searched PubMed, EMBASE and The Cochrane library (January 2018) for cohort studies examining the association between hormonal secretion on overall or recurrence-free survival in ACC.

Methods: A random-effects model meta-analysis was performed to obtain a weighted relative risk comparing cortisolsecreting and/or androgen-secreting ACCs to non-secreting tumours regarding overall and recurrence-free survival. Risk of bias assessment was performed for all studies included.

Results: Nineteen publications were included representing a total of 3814 patients. Most studies were generally considered low/intermediate risk of bias. Meta-analysis showed higher mortality risk for cortisol-secreting ACCs, weighted relative risk 1.71 (95\% Cl: 1.18-2.47) combining studies that adjusted for tumour stage; also a higher recurrence risk was found for cortisol producing $\mathrm{ACCs}$, relative risk 1.43 (95\% Cl: 1.18-1.73). Androgen secretion was not clearly associated with survival (RR: $0.82,95 \% \mathrm{Cl}: 0.60-1.12$ ).

Conclusion: This systematic review and meta-analysis show that cortisol-secreting ACCs are associated with a worse overall survival; future research is needed to establish whether this association points to negative effects of cortisol action, whether it signifies a more aggressive ACC subtype or whether cortisol is merely a prognostic marker.
\end{abstract}

\section{Introduction}

Adrenocortical carcinoma (ACC) is a rare tumour with an incidence of less than 2 per million population. The prognosis remains poor with a 5-year overall survival of less than $50 \%$ and in metastatic disease less than
C) 2018 European Society of Endocrinology Printed in Great Britain
$20 \%(1,2,3,4,5)$. Recurrences are frequent, even after apparent complete surgical resection. Symptoms of hormonal excess (Cushing syndrome, virilization) and abdominal tenderness are common ways of presentation but incidental discovery of an adrenal mass on CT or MRI is becoming increasingly common, currently in

Published by Bioscientifica Ltd. 
more than $15 \%$ of ACC diagnoses $(2,6)$. The hallmark of ACC treatment remains complete surgical resection (5). Adjuvant mitotane treatment is currently considered to have a positive effect on survival rates, although data from randomized control trials are lacking (7).

In recent years, considerable efforts were made to determine tumour characteristics influencing survival, which was well established for tumour stage, age and completeness of resection $(8,9,10)$. In recent years, larger studies have reported on overall and recurrence-free survival of hormone-secreting ACCs (cortisol, androgens or aldosterone) (2). Potentially, hormone excess such as in cortisol-secreting ACC could influence prognosis. Cushing's syndrome is known to decrease overall survival, mainly due to long-term cardiovascular complications even after complete remission $(11,12,13)$. Also the effects of hypercortisolism on infection risks are well known (13). Cortisol excess is also associated with a transcriptome signature related to an aggressive ACC subtype (14).

The prognostic role of ACC hormonal functional status, overt cortisol secretion as well as overt androgen secretion in ACCs, was investigated in this systematic review and meta-analysis.

\section{Methods}

\section{Study selection}

We searched for publications assessing the prognostic role of tumour functional status in ACCs, overt cortisol secretion as well as overt androgen secretion. PubMed, EMBASE and The Cochrane Library were searched January 2018 (Supplementary data 1, see section on supplementary data given at the end of this article). RCTs or cohort studies published after 1990 on the prognostic role of adrenocortical hormones in ACC were eligible. Publications were considered eligible if the study reported a ratio measure (relative risk (RR), odds ratio, hazard ratio (HR)) for hormone secretion (specific hormone or hormonal functional status in general) on overall or recurrence-free survival. Publications that did not provide a ratio measure were eligible if they provided raw data in the article or supplementary data (number of events/ total number of patients for functional vs non-functional tumours).

Publications that included adenomas and publications with a sample size $<50$ were not considered. Only publications in English were eligible. We further assessed potentially eligible publications for overlap. In case of
$>25 \%$ overlap, the publication with the smallest sample size was excluded. When two publications used the same patient group but reported on different outcomes we included both publications and used the largest study to extract patient characteristics.

\section{Data extraction}

Data extraction was performed by two authors independently (TV and OMD). We tried to retrieve missing data by emailing the corresponding author. Extracted data included first author, hospital location, year of publication, starting and final year of patient recruitment, study design, number of included patients, age, sex, stage, recurrence and overall survival in years, tumour grade, tumour size, number of functional tumours, cortisol-secreting tumours, androgen-secreting tumours, aldosterone-secreting tumours, multiple hormonessecreting tumours, number lost to follow-up.

\section{Definition of hypersecretion and assessment method}

The European Society of Endocrinology/European Network of the Study of Adrenal Tumours (ENSAT) guideline suggests hormonal evaluation of clinically non-functional adrenocortical tumours using a $1 \mathrm{mg}$ dexamethasone suppression test (assessing glucocorticoid excess) and screening for increased aldosterone and suppressed renin levels and hypersecretion of androgens (15). Given most publications included patients from multiple centres, and often details on biochemical work-up were not provided, we relied on the author's definitions in use for the definition of hormone-secreting ACCs. We aimed to extract data for cortisol-and androgensecreting ACCs separately; however, in some studies ACC were classified as functional in general.

\section{Risk of bias assesment}

We used a component approach for risk of bias analysis, judging all publications individually. The following elements were assessed:

- histological confirmed in almost all ACC (>95\%) was considered low risk of bias; histological confirmation in $90-95 \%$ was considered intermediate risk; otherwise as high risk of bias;

- inclusion of consecutive ACCs (inclusion of all ACCs according to the predetermined eligibility criteria of the study) was considered low risk of bias; 
- loss to follow-up: 5-10\% was considered intermediate risk of bias; more than $10 \%$ or loss to follow-up was not mentioned articles was considered high risk of bias;

- biochemical confirmation of ACC functional status: publications that used only clinical parameters were considered high risk; publications that included biochemical ACC or clinical confirmed functional ACC were considered intermediate risk of bias; publications using biochemical assessment in all ACC were considered low risk of bias;

- missing data on secretion of ACCs: if more than 5\% of values were missing or no report was made on this issue articles, were considered high bias risk;

- statistical adjustment for age and tumour stage was considered low risk of bias, adjusting for age or tumour stage was considered intermediate risk of bias and adjusting for none was considered high risk;

- non-standardized follow-up procedures were considered high risk of bias.

\section{Statistical analysis}

Heterogeneity was first assessed by visual inspection of the forest plot. Study-specific estimates and their CIs or standard errors were used for meta-analyses. RRs were pooled in a random effects model. Small study effects were assessed in a funnel plot; funnel plots were provided only if more than five studies were available. $I^{2}$ was used to quantify statistical heterogeneity between publications (16). We conducted a meta-regression to quantify the difference between risk measures unadjusted and adjusted for tumour stage.

\section{Results}

\section{Study inclusion and study characteristics}

Of 1523 eligible publications, nineteen (eighteen cohort studies, one RCT $(1,4,7,17,18,19,20,21,22$, $23,24,25,26,27,28,29,30,31,32)$ ) were included, representing a total of 3814 patients (Fig. 1 for flow-chart of study inclusion). All publications except one (17) were published after the year 2000; eleven publications (57\%) were published between 2012 and 2017. Publications included 76 to 524 patients. Four publications included less than 100 patients and five publications more than 300 patients. Eight publications excluded children; one study (18) included children only. The average follow-up time across publications was 42.5 months. The average age at diagnosis across publications ranged from 42 to 52 years,

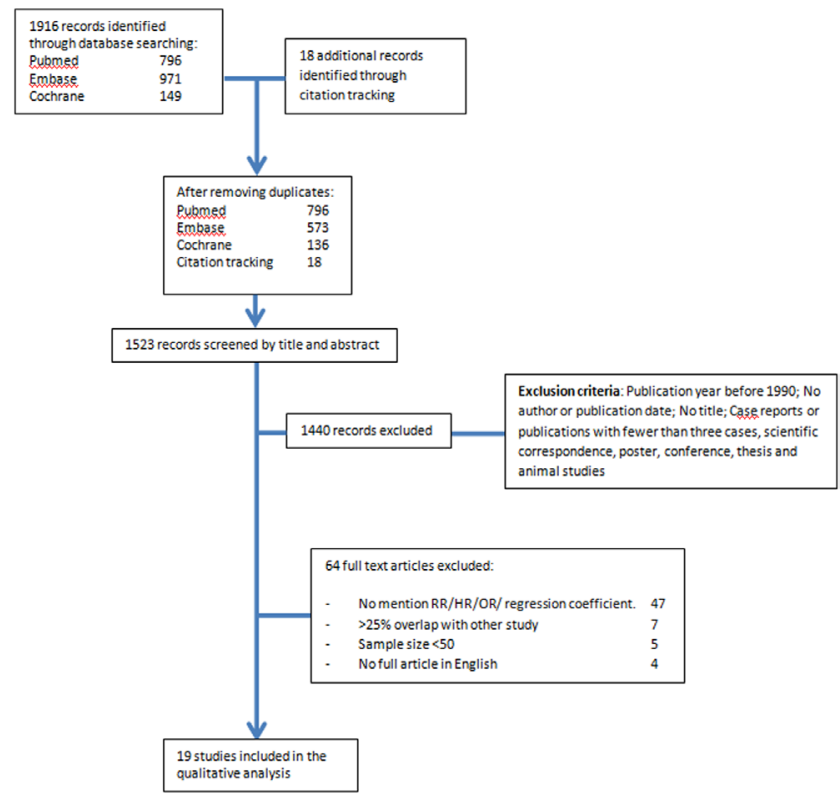

Figure 1

Search strategy.

with the exception of the study in children (18). Thirteen publications included all stages of ACC; two publications investigated stage IV disease only. In total, 102 patients had stage I, 961 stage II, 1063 stage III and 1138 had stage IV ACC. Overall, average tumour size was $11.5 \mathrm{~cm}$ (Supplementary data 2 for details of included studies).

Definition of functional ACC differed across publications. Eight publications defined hypersecretion biochemically. Three publications added clinical symptoms of hormonal secretion as a criterion. Four studies defined clinical symptoms of hormonal secretion as the only criterion, one publication defined hormonal secretion as the presence of either clinical symptoms or biochemical secretion. In the remaining three publications, a definition was missing.

\section{Risk of bias assessment}

Of nineteen included publications, seven had a low, six had an intermediate and six had a high risk of bias (supplementary data 3 for risk of bias assessment of all included studies). ACC diagnosis of tumour functional status was often not (completely) based on biochemical evidence (5/19 publications) or it was not reported how tumour functional status was defined (3/19). Only two publications reported standardised follow-up procedures. Eleven publications had more than 5\% missing secretion values and only 3/19 publications adjusted for both age and tumour stage. 


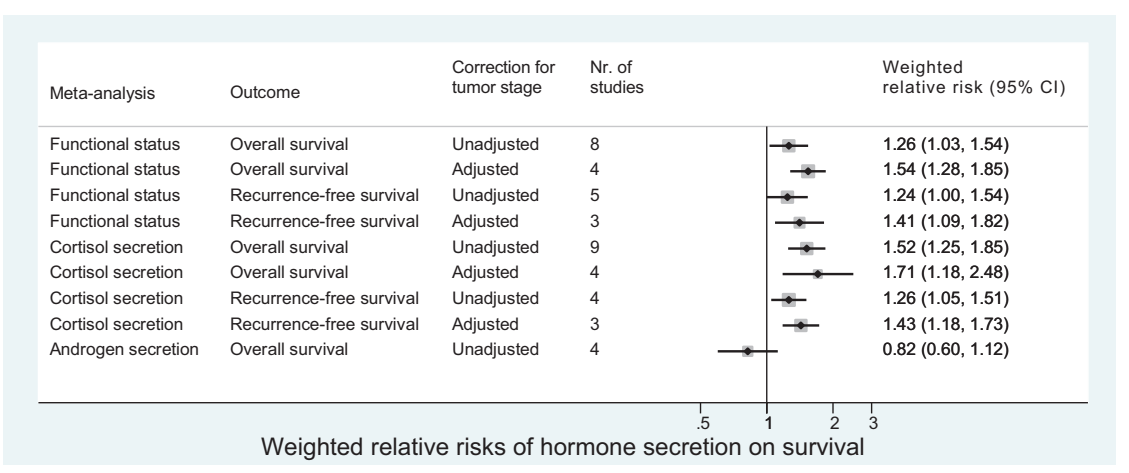

\section{Figure 2}

Weighted relative risks of hormonesecreting ACCs for overall survival.

\section{Meta-analysis of functional ACCs}

Of all ACCs, 50.4\% was considered functional. Nine publications reported on the relationship of all-sort functional status and overall survival, with reported relative mortality risk measures ranging from 0.70 to 2.30. All but one study suggested a decreased survival in hormonal functioning ACC. We pooled data from unadjusted and adjusted models (for tumour stage) separately (Fig. 2). The weighted RR for overall survival was 1.26 (95\% CI: 1.03-1.54) for unadjusted estimates (8 publications, 1453 patients) and 1.54 (95\% CI: $1.28-$ 1.85 ) in data from models adjusting for tumour stage (4 publications, 1199 patients). Heterogeneity was $I^{2}=51 \%$ in unadjusted and $I^{2}=0 \%$ in data from models adjusting for tumour stage (Fig. 2 and Supplementary data 6).

Seven publications reported on the relationship of functional status and recurrence-free survival, with a reported RR ranging 1.00 to 1.80 . In a meta-analysis, the weighted RR for recurrence in the unadjusted estimates (five publications, 1030 patients) was 1.24 (95\% CI: 1.001.54) and 1.41 (95\% CI: 1.09-1.81) in data from three publications (538 patients) adjusting for tumour stage (Fig. 2 and Supplementary data 7).

\section{Meta-analysis cortisol-secreting ACCs}

Cortisol secretion was reported in $36.5 \%$ of ACCs. Nine publications (2252 patients) reported on overall survival, of which four (1351 patients) provided data from a model adjusting for tumour stage. Reported mortality risk measures ranged 1.05 to 3.94 , all pointing towards an increased mortality in cortisol-secreting ACCs.

The weighted relative risk for mortality was increased in cortisol-secreting ACCs compared to non-cortisolsecreting ACCs in the analysis with unadjusted estimates, RR: 1.52 (95\% CI: 1.25-1.85) and adjusted estimates, RR: 1.71 (95\% CI: $1.18-2.47)$, with $I^{2}$ of $80 \%$ and $74 \%$ respectively (Fig. 3).
All four publications (1453 patients) reporting on recurrence-free survival reported a worse recurrence-free survival in cortisol-secreting ACCs, risk measures ranging from 1.04 to 2.59 . The weighted RR for recurrence for publications with unadjusted estimates was $1.26(95 \%$ CI: $1.05-1.51) ; I^{2}=88 \%$. After pooling three publications (1149 patients) that provided data from tumour stage adjusting models was the pooled RR was 1.43 (95\% CI: $1.18-1.73$ ); $I^{2}=14 \%$ (Figs 2 and 4 ). Exclusion of the study in children did not change our results (data not shown).

\section{Meta-analysis of androgen-secreting ACCs}

Of all ACCs, $18.5 \%$ produced androgens (with or without other hormones). Only four publications (1032 patients) provided a separate risk measure for androgen secretion: only one of which corrected for tumour stage (19). RR measures ranged from 0.40 to 1.09 . The weighted RR was 0.82 (95\% CI: $0.60-1.12$ ) with $I^{2}=71 \%$ (Fig. 2 and Supplementary data 8 ). Only one study assessed the effect of aldosterone overproduction (19).

\section{Meta-regression}

We evaluated the difference between unadjusted and adjusted models (for tumour stage) formally using metaregression. All coefficients showed a small increase in effect in data from models adjusting for tumour stage, meaning an underestimation of the effect in studies unadjusted for stage. Meta-regression results are shown in Supplementary data 9.

\section{Discussion}

\section{Main result}

This systematic review and meta-analysis shows that cortisol-secreting ACCs are associated with a worse 


\begin{tabular}{|c|c|c|c|c|c|}
\hline $\begin{array}{l}\text { First } \\
\text { author }\end{array}$ & publication & $\mathrm{N}$ & & $\begin{array}{l}\text { Relativerisk } \\
(95 \% \mathrm{Cl})\end{array}$ & $\begin{array}{l}\% \\
\text { Weight }\end{array}$ \\
\hline Adjusted es & timates (corr & :tion for tumor stage) & & & \\
\hline Margonis & 2016 & 234 & 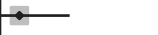 & $1.20(0.74,1.95)$ & 22.04 \\
\hline Else & 2014 & 391 & $\rightarrow$ & $1.43(1.10,1.86)$ & 30.11 \\
\hline Berruti & 2013 & 524 & $\rightarrow$ & $1.55(1.15,2.09)$ & 28.75 \\
\hline Abiven & 2006 & 202 & & $3.94(2.22,6.99)$ & 19.10 \\
\hline Subtotal $(\mathrm{I}$ & squared $=74$ & $\%, p=0.009)$ & & $1.71(1.18,2.47)$ & 100.00 \\
\hline Unadjusted & estimates & & & & \\
\hline Berruti & 2013 & 524 & 5 & $1.05(0.91,1.21)$ & 14.90 \\
\hline Fassnacht & 2012 & 304 & $\rightarrow$ & $1.19(1.06,1.33)$ & 15.35 \\
\hline Icard & 2001 & 253 & $\rightarrow$ & $1.31(1.05,1.63)$ & 13.36 \\
\hline Assie & 2007 & 76 & & $1.32(0.75,2.32)$ & 6.82 \\
\hline Else & 2014 & 391 & $\rightarrow$ & $1.42(1.11,1.83)$ & 12.77 \\
\hline Ceccheto & 2016 & 82 & & $1.47(0.90,2.38)$ & 8.08 \\
\hline Gonzalez & 2007 & 186 & $\longrightarrow$ & $2.27(1.56,3.31)$ & 10.07 \\
\hline Abiven & 2006 & 202 & $\rightarrow$ & $2.33(1.51,3.60)$ & 8.96 \\
\hline Margonis & 2016 & 234 & & $2.71(1.82,4.03)$ & 9.68 \\
\hline Subtotal (I- & squared $=8 C$ & $\%, p=0.000)$ & $\diamond$ & $1.52(1.25,1.85)$ & 100.00 \\
\hline NOTE: Wei & ghts are from & andom effects analysis & & & \\
\hline & & $\begin{array}{l}1 \\
.5\end{array}$ & $\begin{array}{ll}1 & 1 \\
2 & 3\end{array}$ & & \\
\hline
\end{tabular}

overall survival. This finding was robust as all individual publications report a higher mortality risk in cortisolsecreting ACCs. Recurrence risk was also higher in producing than in non-producing ACCs. Androgen secretion was not clearly associated with a worse prognosis; however, data on androgen-secreting ACCs are limited and its prognostic relevance thus uncertain.

\section{Limitations}

An important limitation of this systematic review is that articles providing a nonsignificant relationship for hormone secretion often did not report estimates adjusted for tumour stage. In some cases, adjustment for tumour stage seemed to be performed but was not reported due to lack of statistical significance. Importantly, the cortisol-

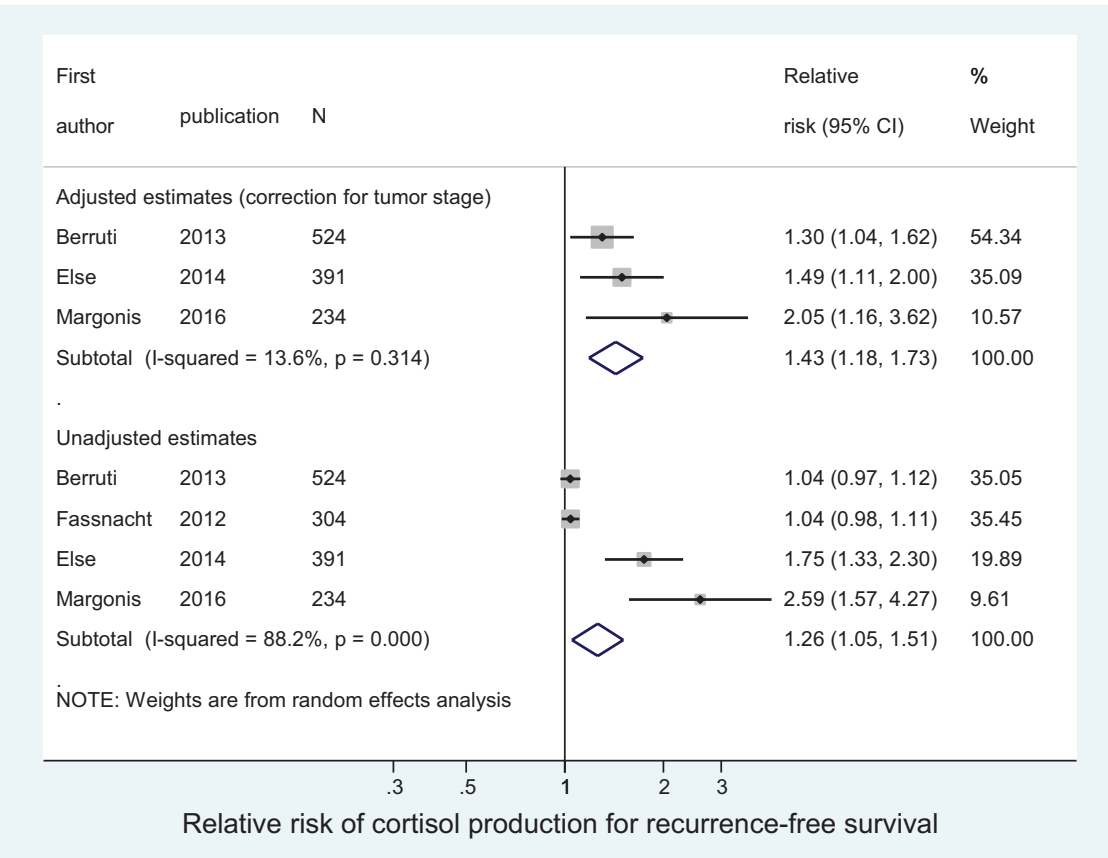

Figure 3

Weighted relative risk of cortisol-secreting ACCs for overall survival.

\section{Figure 4}

Weighted relative risk of cortisol-secreting ACCs for recurrence-free survival. 
mortality association was not largely affected by statistical adjustment, and if anything, the associations were more pronounced. Despite these considerations we cannot exclude the possibility that (unmeasured) confounding is partly explains the results, which is in line with the general agreement that a meta-analysis of observational studies is not establishing causality formally. A second limitation was the difference in definition of hormonal excess. If a clear definition was provided, it was based on clinical and/or biochemical parameters, depending on the publication. A third limitation is the problem of overlapping cohorts. Since ACC is a rare disease (part of), the same patients are analysed in different publications. We restricted inclusion to publications with an overlap $<25 \%$ but we acknowledge that a considerable percentage of overlap sometimes remains. A final limitation is the way data were presented. Most, but not all, publications provided us with (the possibility to calculate) a HR, but in some cases, we had to settle for the RR in which time-toevent is not accounted for.

\section{Interpretation}

Included publications robustly report a worse overall survival and higher recurrence risk in cortisolsecreting ACC. The interpretation of this finding is not straightforward, and a meta-analysis does not formally establish causality. A higher mortality risk could be explained by the negative effect of cortisol action on the immune and the cardiovascular system. This explanation is in line with the increased mortality risk in patients with Cushing's disease from benign causes; and this increased mortality risk was not only shown compared to the general population (13), but was also apparent when comparing Cushing's disease to other pituitary adenomas (33). However, the finding of a higher recurrence risk cannot convincingly be explained by cortisol action. One explanation is that cortisol signifies ACCs with a more aggressive behaviour. Recent research shows that cortisol excess is associated with a transcriptome signature related to aggressive subtype of ACC (14). However, we acknowledge that publication bias, only positive associations reported, may be another explanation.

Quite a substantial number of the ACCs included in this systematic review produced multiple hormones (30\%). It is plausible that the negative effect of tumour functional status on survival is mainly related cortisol secretion. It is less likely that this effect is caused by another hormone since androgen and aldosterone (cortisol secretion is often accompanied by androgen secretion) were not associated with overall survival, but data on these hormones are scarce and more research is required to make more firm conclusions about aldosterone- and androgen-secreting ACCs (20).

\section{Clinical relevance}

When considering ACC prognosis, clinicians can take functional status of the tumour into account as an additional prognostic marker.

\section{Conclusion}

This systematic review and meta-analysis shows that cortisol-secreting ACCs have a worse overall survival; future research is needed to establish whether this association points to negative effects of cortisol action, whether it signifies a more aggressive ACC subtype or whether cortisol is merely a prognostic marker.

Supplementary data

This is linked to the online version of the paper at https://doi.org/10.1530/ EJE-18-0450.

Declaration of interest

Authors Fassnacht $\mathrm{M}$ and Dekkers $\mathrm{OM}$ are editors of the European Journal of Endocrinology. The other authors declare that there is no conflict of interest that could be perceived as prejudicing the impartiality of this study.

\section{Funding}

This research did not receive any specific grant from any funding agency in the public, commercial or non-profit sector.

\section{Acknowledgement}

The authors thank Dr Habra (Ayala-Ramirez et al.) for providing additional information.

\section{References}

1 Fassnacht M, Terzolo M, Allolio B, Baudin E, Haak H, Berruti A, Welin S, Schade-Brittinger C, Lacroix A, Jarzab B et al. Combination chemotherapy in advanced adrenocortical carcinoma. New England Journal of Medicine 2012366 2189-2197. (https://doi.org/10.1056/ NEJMoa1200966)

2 Else T, Kim AC, Sabolch A, Raymond VM, Kandathil A, Caoili EM, Jolly S, Miller BS, Giordano TJ \& Hammer GD. Adrenocortical carcinoma. Endocrine Reviews 201435 282-326. (https://doi. org/10.1210/er.2013-1029)

3 Fassnacht M, Johanssen S, Quinkler M, Bucsky P, Willenberg HS, Beuschlein F, Terzolo M, Mueller HH, Hahner S \& Allolio B. Limited prognostic value of the 2004 International Union Against Cancer staging classification for adrenocortical carcinoma: proposal for a 
Revised TNM Classification. Cancer 2009115 243-250. (https://doi. org/10.1002/cncr.24030)

4 Libe R, Borget I, Ronchi CL, Zaggia B, Kroiss M, Kerkhofs T, Bertherat J, Volante M, Quinkler M, Chabre O et al. Prognostic factors in stage III-IV adrenocortical carcinomas (ACC): an European Network for the Study of Adrenal Tumor (ENSAT) study. Annals of Oncology 201526 2119-2125. (https://doi.org/10.1093/annonc/ mdv329)

5 Bilimoria KY, Shen WT, Elaraj D, Bentrem DJ, Winchester DJ, Kebebew E \& Sturgeon C. Adrenocortical carcinoma in the United States: treatment utilization and prognostic factors. Cancer 2008113 3130-3136. (https://doi.org/10.1002/cncr.23886)

6 Johanssen S, Hahner S, Saeger W, Quinkler M, Beuschlein F, Dralle H, Haaf M, Kroiss M, Jurowich C, Langer P et al. Deficits in the management of patients with adrenocortical carcinoma in Germany. Deutsches Ärzteblatt International 2010107 885-891. (https://doi. org/10.3238/arztebl.2010.0885)

7 Terzolo M, Angeli A, Fassnacht M, Daffara F, Tauchmanova L, Conton PA, Rossetto R, Buci L, Sperone P, Grossrubatscher E et al. Adjuvant mitotane treatment for adrenocortical carcinoma. New England Journal of Medicine 2007356 2372-2380. (https://doi. org/10.1056/NEJMoa063360)

8 Beuschlein F, Weigel J, Saeger W, Kroiss M, Wild V, Daffara F, Libe R, Ardito A, Al Ghuzlan A, Quinkler M et al. Major prognostic role of Ki67 in localized adrenocortical carcinoma after complete resection. Journal of Clinical Endocrinology and Metabolism 2015100 841-849. (https://doi.org/10.1210/jc.2014-3182)

9 Fassnacht M, Libe R, Kroiss M \& Allolio B. Adrenocortical carcinoma: a clinician's update. Nature Reviews Endocrinology 20117 323-335. (https://doi.org/10.1038/nrendo.2010.235)

10 Volante M, Buttigliero C, Greco E, Berruti A \& Papotti M. Pathological and molecular features of adrenocortical carcinoma: an update. Journal of Clinical Pathology 200861 787-793. (https://doi. org/10.1136/jcp.2007.050625)

11 Lindholm J, Juul S, Jorgensen JO, Astrup J, Bjerre P, FeldtRasmussen U, Hagen C, Jorgensen J, Kosteljanetz M, Kristensen L et al. Incidence and late prognosis of Cushing's syndrome: a population-based study. Journal of Clinical Endocrinology and Metabolism 200186 117-123. (https://doi.org/10.1210/ jcem.86.1.7093)

12 Clayton RN, Jones PW, Reulen RC, Stewart PM, Hassan-Smith ZK, Ntali G, Karavitaki N, Dekkers OM, Pereira AM, Bolland M et al. Mortality in patients with Cushing's disease more than 10 years after remission: a multicentre, multinational, retrospective cohort study. Lancet Diabetes and Endocrinology 20164 569-576. (https://doi. org/10.1016/S2213-8587(16)30005-5)

13 Dekkers OM, Horvath-Puho E, Jorgensen JO, Cannegieter SC, Ehrenstein V, Vandenbroucke JP, Pereira AM \& Sorensen HT. Multisystem morbidity and mortality in Cushing's syndrome: a cohort study. Journal of Clinical Endocrinology and Metabolism 201398 2277-2284. (https://doi.org/10.1210/jc.2012-3582)

14 Zheng S, Cherniack AD, Dewal N, Moffitt RA, Danilova L, Murray BA, Lerario AM, Else T, Knijnenburg TA, Ciriello G et al. Comprehensive pan-genomic characterization of adrenocortical carcinoma. Cancer Cell 201629 723-736. (https://doi.org/10.1016/j.ccell.2016.04.002)

15 Fassnacht M, Arlt W, Bancos I, Dralle H, Newell-Price J, Sahdev A, Tabarin A, Terzolo M, Tsagarakis S \& Dekkers OM. Management of adrenal incidentalomas: European Society of Endocrinology Clinical Practice Guideline in collaboration with the European Network for the Study of Adrenal Tumors. European Journal of Endocrinology 2016 175 G1-G34. (https://doi.org/10.1530/EJE-16-0467)

16 Higgins JP \& Thompson SG. Quantifying heterogeneity in a metaanalysis. Statistics in Medicine 200221 1539-1558. (https://doi. org/10.1002/sim.1186)

17 Schulick RD \& Brennan MF. Adrenocortical carcinoma. World Journal of Urology 199917 26-34. (https://doi.org/10.1007/s003450050101)
18 Cecchetto G, Ganarin A, Bien E, Vorwerk P, Bisogno G, Godzinski J, Dall'Igna P, Reguerre Y, Schneider D, Brugieres L et al. Outcome and prognostic factors in high-risk childhood adrenocortical carcinomas: a report from the European Cooperative Study Group on Pediatric Rare Tumors (EXPeRT). Pediatric Blood and Cancer 201764 e26368. (https://doi.org/10.1002/pbc.26368)

19 Else T, Williams AR, Sabolch A, Jolly S, Miller BS \& Hammer GD. Adjuvant therapies and patient and tumor characteristics associated with survival of adult patients with adrenocortical carcinoma. Journal of Clinical Endocrinology and Metabolism 201499 455-461. (https:// doi.org/10.1210/jc.2013-2856)

20 Kendrick ML, Curlee K, Lloyd R, Farley DR, Grant CS, Thompson GB, Rowland C, Young Jr WF, Van Heerden JA, Duh QY et al. Aldosterone-secreting adrenocortical carcinomas are associated with unique operative risks and outcomes. Surgery 2002132 1008-1012. (https://doi.org/10.1067/msy.2002.128476)

21 Berruti A, Fassnacht M, Haak H, Else T, Baudin E, Sperone P, Kroiss M, Kerkhofs T, Williams AR, Ardito A et al. Prognostic role of overt hypercortisolism in completely operated patients with adrenocortical cancer. European Urology 201465 832-838. (https://doi.org/10.1016/j. eururo.2013.11.006)

22 Ayala-Ramirez M, Jasim S, Feng L, Ejaz S, Deniz F, Busaidy N, Waguespack SG, Naing A, Sircar K, Wood CG et al. Adrenocortical carcinoma: clinical outcomes and prognosis of 330 patients at a tertiary care center. European Journal of Endocrinology 2013169 891-899. (https://doi.org/10.1530/EJE-13-0519)

23 Margonis GA, Kim Y, Tran TB, Postlewait LM, Maithel SK, Wang TS, Glenn JA, Hatzaras I, Shenoy R, Phay JE et al. Outcomes after resection of cortisol-secreting adrenocortical carcinoma. American Journal of Surgery 2016211 1106-1113. (https://doi.org/10.1016/j. amjsurg.2015.09.020)

24 Grubbs EG, Callender GG, Xing Y, Perrier ND, Evans DB, Phan AT $\&$ Lee JE. Recurrence of adrenal cortical carcinoma following resection: surgery alone can achieve results equal to surgery plus mitotane. Annals of Surgical Oncology 201017 263-270. (https://doi. org/10.1245/s10434-009-0716-x)

25 Postlewait LM, Ethun CG, Tran TB, Prescott JD, Pawlik TM, Wang TS, Glenn J, Hatzaras I, Shenoy R, Phay JE et al. Outcomes of adjuvant mitotane after resection of adrenocortical carcinoma: a 13-institution study by the US Adrenocortical Carcinoma Group. Journal of the American College of Surgeons 2016222 480-490. (https://doi. org/10.1016/j.jamcollsurg.2015.12.013)

26 Abiven G, Coste J, Groussin L, Anract P, Tissier F, Legmann P, Dousset B, Bertagna X \& Bertherat J. Clinical and biological features in the prognosis of adrenocortical cancer: poor outcome of cortisolsecreting tumors in a series of 202 consecutive patients. Journal of Clinical Endocrinology and Metabolism 200691 2650-2655. (https:// doi.org/10.1210/jc.2005-2730)

27 Ip JC, Pang TC, Glover AR, Soon P, Clarke S, Richardson A, Campbell P, Robinson BG \& Sidhu SB. Improving outcomes in adrenocortical cancer: an Australian perspective. Annals of Surgical Oncology 201522 2309-2316. (https://doi.org/10.1245/s10434-0144133-4)

28 Loncar Z, Djukic V, Zivaljevic V, Pekmezovic T, Diklic A, Tatic S, Dundjerovic D, Olujic B, Slijepcevic N \& Paunovic I. Survival and prognostic factors for adrenocortical carcinoma: a single institution experience. BMC Urology 201515 43. (https://doi.org/10.1186/ s12894-015-0038-1)

29 Assie G, Antoni G, Tissier F, Caillou B, Abiven G, Gicquel C, Leboulleux S, Travagli JP, Dromain C, Bertagna X et al. Prognostic parameters of metastatic adrenocortical carcinoma. Journal of Clinical Endocrinology and Metabolism 200792 148-154. (https://doi. org/10.1210/jc.2006-0706)

30 Icard P, Goudet P, Charpenay C, Andreassian B, Carnaille B, Chapuis Y, Cougard P, Henry JF \& Proye C. Adrenocortical carcinomas: surgical trends and results of a 253-patient series from 
the French Association of Endocrine Surgeons study group. World Journal of Surgery 200125 891-897. (https://doi.org/10.1007/s00268001-0047-y)

31 Hermsen IGC, Kerkhofs TMA, Butter Gd, Kievit J, van Eijck CHJ, Nieveen van Dijkum EJM \& Haak HR. Surgery in adrenocortical carcinoma: importance of national cooperation and centralized surgery. Surgery 2012152 50-56. (https://doi.org/10.1016/j.surg.2012.02.005)

32 Gonzalez RJ, Tamm EP, Ng C, Phan AT, Vassilopoulou-Sellin R, Perrier ND, Evans DB \& Lee JE. Response to mitotane predicts outcome in patients with recurrent adrenal cortical carcinoma. Surgery 2007142 867-875; discussion 867-875. (https://doi. org/10.1016/j.surg.2007.09.006)

33 Dekkers OM, Biermasz NR, Pereira AM, Roelfsema F, van Aken MO, Voormolen JHC \& Romijn JA. Mortality in patients treated for Cushing's disease is increased, compared with patients treated for nonfunctioning pituitary macroadenoma. Journal of Clinical Endocrinology and Metabolism 200792 976-981. (https://doi. org/10.1210/jc.2006-2112)

Received 29 May 2018

Revised version received 23 September 2018

Accepted 1 October 2018 